\title{
A PROPOSIÇÃO DO CURSO SUPERIOR DE TECNOLOGIA PARA FORMAÇÃO DO TRABALHADOR DE NOVO TIPO
}

\author{
THE PROPOSITION OF THE HIGHER TECHNOLOGY COURSE \\ FOR THE NEW TYPE OF WORKER \\ LA PROPUESTA DEL CURSO SUPERIOR DE TECNOLOGÍA PARA
LA FORMACIÓN DE TRABAJADORES DE NUEVO TIPO
}

\author{
Célia Cristina Pereira da Silva Veiga \\ (PPGEduc/UFRRJ, Brasil) \\ Bruno de Oliveira Figueiredo \\ (FAETEC/RJ, Brasil)
}

\section{doi) https://doi.org/10.29404/rtps-v5i8.376}

RESUMO: com a evidência da crise orgânica do capital, a recomposição burguesa é expressa por amplo processo de reestruturação produtiva e redefinição dos mecanismos de mediação do conflito de classes. Esse processo impulsiona a formulação de diversos instrumentos voltados à formação do novo tipo de trabalhador segundo as demandas do mercado. Com essa problemática, definimos como objeto o projeto de criação e desenvolvimento dos cursos superiores de tecnologia. Nosso objetivo é analisar o papel desses cursos na formação para o trabalho. Para isso, tomamos como referência as formulações do Banco Mundial, da Organização das Nações Unidas para a Educação, a Ciência e a Cultura (UNESCO) e da Comissão Econômica para América Latina e Caribe (CEPAL). Os resultados evidenciam a imposição do ensino superior tecnológico como estratégia para formação e conformação da classe trabalhadora à sociabilidade burguesa.

Palavras-Chave: Hegemonia, Burguesia, Neoliberalismo e Educação, Política de formação profissional, Curso superior de tecnologia.

ABSTRACT: with the evidence of the organic crisis of capital, the bourgeois recompositing is expressed by a broad process of productive restructuring and redefinition of the mechanisms of mediation of the class conflict. This process encourages the formulation of various instruments aimed at training the new type of worker according to market demands. With this problem, we defined as object the project of creation and development of the higher technology courses. Our goal is to analyze the role of these courses in job training. For this, we take as a reference the formulations of the World Bank, the United Nations Educational, Scientific and Cultural Organization (UNESCO) and the Economic Commission for Latin America and the Caribbean $(E C L A C)$. The results show the imposition of technological higher education as a strategy for training and shaping the working class to bourgeois sociability.

Keywords: Hegemony, Bourgeoisie, Neoliberalism, Vocational training policy, Higher technology course.
RESUMEN: con la evidencia de la crisis orgánica del capital, la recomposición burguesa se expresa mediante un amplio proceso de reestructuración productiva y redefinición de los mecanismos de mediación del conflicto de clases. Este proceso impulsa la formulación de varios instrumentos destinados a capacitar al nuevo tipo de trabajador de acuerdo con las demandas del mercado. Con este problema, definimos como objeto el proyecto de creación y desarrollo de los cursos superiores de tecnología. Nuestro objetivo es analizar el papel de estos cursos en la capacitación laboral. Para ello, tomamos como referencia las formulaciones del Banco Mundial, la Organización de las Naciones Unidas para la Educación, la Ciencia y la Cultura (UNESCO) y la Comisión Económica para América Latina y el Caribe (CEPAL). Los resultados muestran la imposición de la educación superior tecnológica como estrategia para capacitar y moldear a la clase trabajadora en la sociabilidad burguesa.

Palabras Clave: Hegemonía, Burguesía, Neoliberalismo, Política de formación profesional, Curso superior de tecnología. 


\section{Introdução}

Como parte de uma pesquisa voltada para explicar o papel da expansão do ensino superior tecnológico no contexto brasileiro, neste artigo, apresentamos uma análise sobre o papel dos Cursos Superiores de Tecnologia (CST) na formação para o trabalho. Nossa análise toma como referência o contexto da crise orgânica do capital e da decorrente recomposição burguesa pela manutenção da hegemonia burguesa nas dimensões socioeconômica e política.

Nossa compreensão da recomposição burguesa envolve a dinâmica de reordenamento da dimensão do trabalho e da produção, combinada com mudanças nas relações de poder expressas na contrarreforma do Estado. Com base nesta problemática que envolve os CST em um reordenamento do trabalho educacional, em âmbito mundial, estabelecemos como objeto a pedagogia política evidenciada nas formulações dos organismos internacionais voltadas para a ressignificação e reestruturação da educação superior como "educação terciária", tomando como foco a educação profissional tecnológica.

Nossa investigação está fundamentada no desenvolvimento de uma pesquisa básica, com análise qualitativa e caráter explicativo, com procedimentos classificados na pesquisa documental.

Na primeira parte do texto buscamos estabelecer as relações entre recomposição burguesa, pedagogia política renovada do capital e o desenvolvimento da concepção de "educação terciária", delineando os determinantes sócio-históricos da expansão dos CST no contexto brasileiro.

Em um segundo tópico, apresentamos as ações e formulações dos organismos internacionais na proposição e indução dos CST como uma das estratégias de reestruturação e de ressignificação da educação superior fundamentada na concepção de "educação terciária".

Para alcançar o objetivo de nosso texto, na terceira parte, estabelecemos as relações entre o desenvolvimento dos CST e seu papel na formação do trabalhador de novo tipo. Esta reflexão identifica os aspectos da formação necessária à manutenção da hegemonia e à renovação da sociabilidade burguesa em um contexto de crise orgânica do capital.

\section{Recomposição burguesa e pedagogia política do capital}

Em movimento mundializado, a crise orgânica do capital já apresentava sinais no começo dos anos 1960, porém, sua dimensão ampliada fica explícita no final dos anos 1960 e início dos anos 1970. Neste contexto, a recomposição burguesa se desenvolve com a mesma intensidade em que a crise orgânica do capital se aprofunda e seu movimento ampliado dá sentido a mudanças socioeconômicas e políticas. É com o aprofundamento desta crise que suas dimensões ficam explícitas na dinâmica da luta de classes, envolvendo 
amplo processo de reestruturação produtiva e redefinição dos mecanismos de mediação do conflito de classes ou a renovação da pedagogia política do capital.

A dinâmica das mudanças nas relações de produção vem se configurando como estratégias de intensificação da precariedade social do trabalho, possibilitada pela inserção intensa de ciência e tecnologia na produção, combinada com novos modelos de gestão do trabalho e da produção (SOUZA, 2016, 2019). Seus impactos caracterizam a redução contínua e substancial do trabalho vivo, a otimização de tempos e movimentos, como enxugamento de tempos mortos e flexibilização do trabalho e dos processos produtivos (SOUZA, 2016; 2019).

As mudanças no mundo do trabalho e na dinâmica da produção se configuram em estratégias políticas e econômicas para a renovação da sociabilidade burguesa. $\mathrm{Na}$ dinâmica da luta de classes estas mudanças desencadeadas pela administração burguesa estabelecem ao mesmo tempo o momento ampliado da racionalização econômica e política do trabalho. As relações entre trabalho e educação, entre racionalização psicofísica e ético-política ficam explícitas no caráter coletivo e mediador da administração como instrumento sofisticado de formação-conformação econômica e política do trabalhador individual e coletivo.

O caráter pedagógico-formativo de uma existência fragmentada, precária e subordinada à valorização do capital exige mudanças dinâmicas, inter-relacionadas e constantes em todas as dimensões socioculturais ${ }^{1}$ de produção e reprodução da vida material. Neste sentido, a administração burguesa estabelece forma institucional burocratizada como forma de dominação e expressão da sociabilidade burguesa. Com esta forma, a burocratização amplia o poder burguês consolidando a formação-conformação dos trabalhadores fundamentados na concepção de mundo desta classe. É neste sentido que afirmamos a ocorrência de mudanças inter-relacionadas entre a dinâmica políticopedagógica fabril e as mudanças em toda a institucionalidade burocrática nas esferas da sociedade civil e sociedade política. Assim, os organismos construídos na esfera da sociedade civil possuem forma e conteúdo referenciados nas dimensões política e econômica da cultura fabril, mediadas pela administração burguesa como instrumento da pedagogia política da dominação de classes.

Nesse contexto, a cada período de desenvolvimento do sistema imperialista do capital, a renovação da sociabilidade burguesa estabelece novos sentidos à concepção de cidadania e de democracia. Essa renovação é determinada pela luta de classes como movimento das frações de classes nas esferas da sociedade civil e sociedade política. As formas de captura da consciência humana nos processos formativos e conformativos entremeados na relação trabalho e educação envolvem interior e exterior da institucionalidade burocrática, nas dimensões da sociedade civil e sociedade política. Com

${ }^{1}$ Compreendemos a dimensão cultural com base no conceito gramsciano de cultura, como a forma de ser humana, envolvendo toda a materialidade da práxis humana. 
base neste conjunto de reflexões, a dinâmica de alterações no mundo do trabalho e da produção exigem a formação-conformação de uma cidadania empreendedora fundamentada em uma teia de fetiches de mercado que condicionam a práxis individual e coletiva ao que produz valor de troca. Essa sofisticação das dimensões ideológicas da administração burguesa na dinâmica da recomposição burguesa deve estabelecer formas ampliadas para o conjunto das reações estabelecidas entre sociedade civil e sociedade política inter-relacionando as mudanças no mundo do trabalho e da produção e mudanças na dinâmica de funcionamento do aparelho de Estado como forma de manutenção e dominação de classes.

A cidadania burguesa tem o sentido de legitimação e limitação do movimento das classes subalternas à luta condicionada aos limites da democracia restrita e aos determinantes da institucionalidade burocratizada. É com este sentido que o conteúdo de uma cidadania fundamentada em avanços nos direitos socioeconômicos e políticos deve mudar em um contexto de crise orgânica do capital. A cidadania renovada ganha formas de um "chamado" à salvação do sistema imperialista do capital em um movimento de crise orgânica. A conformação psicofísica e ético-política estabelece na práxis empreendedora o sentido da busca pela manutenção da dinâmica do valor e a naturalização da intensificação da precariedade social do trabalho.

No conjunto da recomposição burguesa, o processo em movimento de hegemonização política e econômica estabelece como momento o renovado regime de acumulação flexível inter-relacionado à redefinição dos mecanismos de mediação do conflito de classes. Assim, a ampliação das formas da cidadania fundamentada em fetiches de mercado deve ocorrer para o conjunto das esferas sociais, desencadeando a combinação do regime de acumulação flexível e o desenvolvimento do projeto de sociabilidade neoliberal com caráter mundial.

A dinâmica do projeto de sociabilidade neoliberal tem como objetivo principal o desmonte da regulação social pautada no Estado de Bem-Estar social, com a direção de mercantilização da vida, ressignificação dos direitos socioeconômicos e políticos como bens e serviços, financeirização da economia, apropriação dos fundos públicos como forma manter a dinâmica de valorização do valor, a naturalização da intensificação da precariedade social do trabalho em nível mundial. É neste sentido que Souza (2019) aponta a intensificação da precariedade social do trabalho como produto da recomposição burguesa. Esse processo de hegemonização do projeto de sociabilidade burguesa encontra obstáculos na reação das classes subalternas desencadeando a ameaça ao bloco no poder. Nos anos 1990, a disputa entre as frações de classes burguesas desencadeia a mudança do bloco no poder e estabelece materialidade ao projeto socialdemocrata como uma mediação do projeto neoliberal - apresentado como uma "Terceira Via".

A mediação do projeto neoliberal sistematizada por Anthony Giddens, em meados dos anos 1990, representa um refinamento da pedagogia política do capital como proposta mundial. Como aspectos desta renovação, as formas de privatização ganham uma institucionalidade potencializada e fundamentada no conceito de público não-estatal. Esta 
sofisticação institucional e burocrática estabelece a diluição das barreiras entre público e privado, permitindo o aprofundamento das formas mercantilizadas na sociabilidade burguesa para as diferentes institucionalidades que estabelecem relações entre o aparelho de Estado e a sociedade civil. Na dinâmica de mercantilização e capitalização da vida, as parcerias público-privadas se constituem em dimensões estruturais para o aprofundamento da sociabilidade burguesa e consolidação da cidadania empreendedora.

Com base na discussão que estabelecemos até o momento, o projeto de sociabilidade burguês em movimento se configura como hegemonização política e econômica das classes subalternas e do condicionamento de toda institucionalidade burguesa que deve manter suas formas e conteúdo voltados para a manutenção do poder de classe. Neste sentido, a educação se torna dimensão estratégica para a formação-conformação das classes subalternas à salvação do ordenamento social imperialista em crise. O "chamado" à desconstrução da regulação social de Bem-Estar para a edificação de uma suposta sociedade do conhecimento ou "sociedade de bem-estar social" caracteriza o fenômeno da atomização humana como estratégia de dominação de classes. Este fenômeno individualiza a luta de classes, com a fragmentação das classes subalternas em grupos, subgrupos e interesses deslocados da condição de classe, além de negar a existência de classes sociais.

Podemos perceber na necessidade visceral de manter toda a produção e reprodução da existência humana à imagem e semelhança da burguesia, como classe dominante, o caráter imperialista e totalizante de sua forma de ordenamento social. É neste sentido que os sistemas educacionais se tornam dimensões estratégicas para o processo de hegemonização com potencialidade para a formação-conformação das classes subalternas ao projeto de sociabilidade burguês. A pedagogia política do capital, expressa em um projeto de sociabilidade mediado pelos teóricos da "Terceira Via", tem como objetivo redefinir a relação entre o aparelho de Estado e a sociedade civil para dar continuidade à dominação burguesa. É com esta pretensão que a contrarreforma estatal envolve todas as dimensões desta relação, materializando a redefinição das políticas públicas e, principalmente, das políticas sociais e seu financiamento, sua decorrente contrarreforma educacional, sua reconfiguração administrativa, expressando a racionalização política e econômica destas dimensões. Neste sentido, o Estado educador do consenso em torno da concepção burguesa de mundo estabelece as dimensões da educação e da administração como campo de disputa por hegemonia estratégicos.

A compreensão dos impactos da recomposição burguesa nos sistemas educacionais brasileiros exige a ampliação da discussão para as concepções de educação em disputa no conjunto da contrarreforma do Estado. Nesse sentido, o conceito de imperialismo total se torna essencial para compreender o papel dos organismos internacionais e da natureza dual do ensino superior tecnológico no Brasil.

Nos anos 1960, o delineamento da crise orgânica do capital e sua compreensão pelos países hegemônicos podem ser evidenciados na influência de organismos internacionais voltada para a educação dos Estados latino-americanos. Com esse objetivo, a readequação 
da administração pública Latino-americana ao novo padrão de desenvolvimento imperialista passa a fazer parte de ações de organismos internacionais voltadas para experiências de contrarreforma estatal. Além de articulações e financiamento de organismos internacionais voltados para a "reforma" da administração pública, a representação da Organização das Nações Unidas para a Educação, a Ciência e a Cultura (UNESCO) é instalada no Brasil em 1964 - mesmo ano do golpe empresarial-militar que instalou o regime ditatorial.

Como estratégias de educação dos Estados Latino-americanos, as primeiras experiências de diversificação e flexibilização dos sistemas educacionais brasileiros podem ser evidenciadas nos anos 1960. Assim, essas experiências dão forma e conteúdo à reformulação da organização escolar e o desenvolvimento de cursos experimentais com flexibilização de currículos, métodos pedagógicos e de avaliação do ensino superior brasileiro materializados na Lei de Diretrizes e Bases da Educação Nacional (LDBEN) $n^{\circ}$ 4.064/1961 (BRASIL, 1961), conforme Santos e Jiménez (2009).

O Banco Internacional de Reconstrução e Desenvolvimento (BIRD) e a United States Agency for International Development (USAID) passam a financiar a criação e consolidação de cursos superiores de curta duração (SANTOS; JIMÉNEZ, 2009). No contexto posterior ao golpe empresarial-militar de 1964, o financiamento da reforma universitária decorre de cooperações internacionais entre o Estado brasileiro e os referidos organismos internacionais (SANTOS; JIMÉNEZ, 2009). O acordo de cooperação entre o Ministério da Educação e Cultura² (MEC) do Brasil e a USAID deu materialidade ao Programa de Desenvolvimento do Ensino Médio e Superior de Curta Duração (PRODEM) (SANTOS; JIMÉNEZ, 2009).

A diversificação e flexibilização das instituições de ensino superior brasileiro passam a fazer parte das ações e formulações dos organismos internacionais estabelecendo sentido e direção às transformações dos Centros Federais de Educação Tecnológica, nos anos 1970, e posteriormente, com a transformação destes em Institutos Federais, nos anos 2000 (SANTOS; JIMÉNEZ, 2009). A articulação entre o MEC e o Banco Mundial foi evidenciada no fenômeno da cefetização da educação profissional, a partir de meados dos anos 1970, e nos anos 2000, com o fenômeno da ifetização da educação profissional. Em contextos diferenciados, esses fenômenos mantêm o sentido da diversificação e flexibilização como fragmentação dos sistemas educacionais brasileiros, moldando o caráter da subsunção da contrarreforma educacional. Com o aprofundamento da crise orgânica do capital, a sofisticação das estratégias da pedagogia política do capital evidencia o caráter de educação interessada, imediatista, pragmática e voltada para os ditames imediatos do mercado (SOUZA, 2018). Com a direção principal do Banco Mundial a educação vem deixando seu significado de direito e assumindo o caráter de bem, mercadoria, expressa no conceito de "educação terciária" (MACEDO, 2017).

2 Atualmente denominado Ministério da Educação, embora continue a utilizar a sigla MEC. 
Nos anos 1990, o conceito de "educação terciária" ganha sentido claro, principalmente, com a hegemonia do projeto neoliberal mediado pela "Terceira Via". Este conceito sistematiza do conjunto de mudanças na direção da mercantilização da educação e redefinição da divisão do trabalho educacional em âmbito mundial. Em nossa análise, as formas de mercantilização ou capitalização da vida ficam explícitas na diversificação e flexibilização dos sistemas educacionais de ensino superior e na desconstrução da educação como direito e reconstrução como bens e serviços. Nesse sentido, o projeto de "educação terciária" é organizado como contraproposta ao projeto universitário de ensino superior, como pode ser observado a seguir:

\begin{abstract}
The phrase "from higher to tertiary education" sets the most recent OECD experience in a new, different key. The term "tertiary education" deliberately signals a break from prior OECD work that focused on "higher education" and, in particular, on institutions, programs and the university. "Post-secondary" is seen as an inappropriate term, at a time when a majority or more-in some countries, substantially more-of a generation are likely to participate in studies at this level at some point over their lifetime. From this "tertiary-wide" and "life-cycle long" perspective, rates of participation already exceed 65 per cent in Australia, Finland, Japan, Korea, the United Kingdom and the United States (on the basis of information supplied by the countries). These rates of participation are markedly higher than those envisaged or projected in the early 1990s. One consequence is that, for current and future cohorts, the tertiary level may replace the secondary level as the reference for foundation learning and for key transitions between education and working life. In this respect and others, "tertiary education" as a term is intended to signal an important shift in orientation, to responsiveness to demand; to inclusiveness; from programs to learners; from a rigid hierarchy of programs and institutions into a breadth of flexible, transparent and inter-connected learning options; from teaching to learning (BANCO MUNDIAL, 2002, p. 89).
\end{abstract}

A fragmentação dos sistemas educacionais pode ser evidenciada na indução à fragmentação institucional, por meio da preferência pela educação superior em estabelecimentos de ensino não-universitário. As particularidades deste projeto para a América Latina ficam explícitas no financiamento e indução dos CST, com a orientação para o desenvolvimento na modalidade de $\mathrm{EaD}$ e, preferencialmente, em instituições privadas diversificadas. Desse modo, as bases do projeto hegemônico para o ensino superior são apresentadas pelos organismos internacionais pelas seguintes pautas: 1) ampliação do acesso ao ensino superior; 2) diversificação das IES e dos tipos de curso; 3) expansão da rede privada; 4) ampliação do uso das Tecnologias da Informação e Comunicação (TIC) com vistas ao desenvolvimento da Educação à Distância (EaD); 5) formação de professores adaptados à nova realidade; 6) melhoria da qualidade da educação superior; 7) desenvolvimento de programas de educação ao longo da vida sob perspectiva de uma educação empresarial; 8) implementação de sistemas de avaliação; 9) fomento à cooperação internacional e mundialização da educação superior; 10) investimento em inovação e em parcerias público-privadas; e, 11) ampliação do nível pós-secundário (UNESCO, 2009).

A partir dessa perspectiva, no Brasil, estão regulamentados os CST, que são cursos superiores de curta duração, com carga horária de 1600 a 2400 horas, que podem ser ofertados na modalidade $\mathrm{EaD}$ e cuja certificação confere as mesmas prerrogativas dos demais níveis acadêmicos. Atualmente, os CST são regulados pelo Decreto $n^{\circ}$ 
5.154/2004 (BRASIL, 2004) e, desde sua implementação, em 1997, pelo Decreto $n^{\circ}$ 2.208/1997 (BRASIL, 1997), esse nível acadêmico se expande, tanto em número de cursos, como em número de matrículas. Desse modo, o CST, no Brasil, é uma realidade consolidada, a despeito das contradições e disputas que existam no seu desenvolvimento.

\section{A atuação dos organismos internacionais na proposição do CST}

A ampla participação de intelectuais orgânicos e aparelhos privados de hegemonia do capital na formulação e condução da política desenvolvida para formação do trabalhador está evidenciada em diversas formas que congregam em torno de si, organicamente, as dimensões da administração clássica. Planejamento, organização, direção e controle estão fundamentados na pedagogia política do capital para difusão e naturalização da concepção de mundo burguesa cuja finalidade é a subsunção total do trabalho ao capital.

No âmbito da política de ensino superior, as mudanças impulsionadas pelas reformas advindas do projeto imperialista e global do capitalismo neoliberal propõem diversos caminhos e instrumentos para formação do trabalhador. Para evidenciar alguns instrumentos acionados no bojo dessa pedagogia política, analisamos documentos do Banco Mundial, da UNESCO e da Comissão Econômica para América Latina e Caribe (CEPAL) que tratam sobre a política de ensino superior. Nosso foco na análise desses documentos é explicitar o fomento ao desenvolvimento dos CST no mesmo período histórico marcado por profundas mudanças oriundas do processo de recomposição burguesa.

Em 1956, durante o Seminário Iberoamericano de Ensino Técnico, realizado em Madri, o ensino técnico/tecnológico superior com duração de 2 e 3 anos, principalmente na área de engenharia, foi apresentado como modelo a ser desenvolvido (UNESCO, 1959, p. 7). Esse modelo em funcionamento, em 1959, no Egito, Jordânia, Síria, Cuba, Iraque, Itália, El Salvador, Turquia, Venezuela, Indonésia, Reino Unido e África do Sul serve de exemplo para os demais países, de acordo com a UNESCO (1959). Além disso, a UNESCO (1959) indicou cerca de 300 bibliografias, nos respectivos idiomas de cada país de referência e, pelo menos, mais de 40 de fontes de consulta de outros materiais, como revistas e periódicos científicos todos com foco na implementação desse tipo de curso.

Em 1962, a CEPAL (1962, p. 155) divulgou três principais linhas de ação para o desenvolvimento econômico na América Latina no campo da educação: 1) Pesquisa e difusão tecnológica; 2) Formação técnica em todos os níveis; e, 3) Transferência da técnica industrial moderna ao empresariado latino-americano. Algumas "recomendações" para a educação superior contidas no Documento são o fomento à ideia de empregabilidade e flexibilidade, parcerias com setor produtivo e empresariado, diversificação de cursos e ampliação do número de vagas para educação técnica em todos os níveis, incluindo o "ensino superior tecnológico" (CEPAL, 1962, p. 218, 219, 223). 
Nesse mesmo ano, a UNESCO (1962) difundiu diretrizes para Educação Profissional Tecnológica (EPT) e se propôs a desenvolver o programa de Educação Científica e Tecnológica Superior para os Estados Membros partindo da criação de outro formato de instituições e de cursos, bem como da modernização dos currículos, materiais didáticos e métodos de ensino. Com esse objetivo, promoveu pesquisas, seminários, cursos, treinamentos, suporte na publicação de relatórios, parcerias no desenvolvimento de pesquisas (UNESCO, 1962, p. 2).

Durante as décadas de 1960 e 1970, diversas ações foram desenvolvidas pela UNESCO a fim de fomentar a política educacional da classe dirigente. Além da produção de livros, revistas, relatórios, diagnósticos etc., a realização da Conferência internacional sobre planejamento educacional, em Paris, em 1968, resultou em uma série de resoluções para política educacional em nível mundial (UNESCO, 1968). Além da Conferência Geral da UNESCO, em 1970, também em Paris, que resultou em uma série de resoluções para política de educação dos países membros e estabeleceu que 1970 seria o Ano Internacional da Educação. Nesse evento, foram delineadas as bases para formulação das políticas educacionais dos Estados Membros e para promoção de um plano internacional com enfoque integrado às estratégias para o desenvolvimento e reforma da educação (UNESCO, 1970, p. 20). No ensino superior, orienta a diversificação e expansão pela organização de modelos diferentes de ensino superior, com base na concepção de educação permanente (UNESCO, 1970, p. 26). O Brasil teve efetiva participação como um dos integrantes do Conselho Internacional de Coordenação.

Em 1968, a Educação Superior brasileira foi reformulada por meio da Lei no 5.540/1968 (BRASIL, 1968) que toma como base o Ato Institucional no 5 , para "modernizar" a educação superior brasileira de acordo com o modelo norte-americano. Essa reforma organizou o nível educacional de acordo com a ideia de racionalização taylorista, aumentou o controle governamental sobre a universidade, direcionou a ênfase da educação superior aos cursos de ciências exatas e de tecnologia, reforçou a administração universitária buscando aumentar a produtividade dos seus recursos humanos e materiais (CUNHA, 1988, p. 317319).

\begin{abstract}
Contudo, um processo mais poderoso se desenvolvia ao largo. A revisão do Plano Nacional de Educação, em 1965, passou a destinar 5\% do Fundo Nacional do Ensino Superior para subvencionar os estabelecimentos particulares do terceiro grau. Esse incentivo financeiro mais a contenção do crescimento dos estabelecimentos do setor público abriram amplas possibilidades para o setor privado no atendimento da demanda reprimida. Capitais tradicionalmente aplicados no ensino de $2^{\circ}$ grau, capitais recém-investidos em cursinhos e capitais de outros setores de atividade transferiram-se para a exploração do promissor mercado do ensino superior. Um quadro exemplar encontrado em muitas cidades brasileiras pode ser traçado assim: um estabelecimento particular de $1^{\circ}$ e $2^{\circ}$ graus passou a abrigar uma faculdade no período noturno; com o crescimento das matrículas, a faculdade ocupa todo o prédio, todos os turnos, deslocando o $1^{\circ}$ e $2^{\circ}$ graus; numa terceira etapa, novas faculdades são justapostas à primeira, até que o conjunto muda de nome, ganhando o status de universidade (CUNHA, 1988, p. 321-322).
\end{abstract}

Em 1969, foi autorizada a organização e o funcionamento dos cursos profissionais superiores de curta duração no Brasil (BRASIL, 1969). No ano seguinte, o Parecer CEE/SP nº 
50/1970 (BRASIL, 2002a) autorizou a instalação e funcionamento dos primeiros CST ofertados pelo Centro Estadual de Educação Tecnológica de São Paulo. O curso visava formar profissionais para que atuassem nas lacunas entre o engenheiro e a mão-de-obra especializada (BRASIL, 2002a). A ação sofreu resistência por parte dos conselhos de classe dos engenheiros e não obteve êxito para além do papel, conforme esperado para aquele momento.

A edição desses marcos legais no Brasil contou com a participação ativa do Banco Mundial na cessão de empréstimos e estabelecimento de acordos de cooperação técnica que tinham como contrapartida a implementação dos CST. Em 1967, o Banco Mundial difundiu um diagnóstico acerca do desenvolvimento econômico no Brasil com propostas para educação (BANCO MUNDIAL, 1967, p. 24). De acordo com esse mesmo Documento, o Brasil não possuía um programa de treinamento para técnicos agrícolas que atendesse à demanda qualitativa e quantitativa de formação de mão-de-obra, tendo em vista que as escolas agrícolas apresentavam alto índice de abandono escolar e os alunos que concluíam os estudos davam seguimento no nível superior. Desse modo, o número de técnicos era inferior ao de engenheiros e veterinários e a demanda do primeiro seria bem maior que a do segundo e terceiro. A criação de escolas técnicas de ciclo superior para diversificação do nível superior, o custeio das mensalidades, o investimento no nível médio e o fomento ao trabalho para os alunos foram sugeridos no Documento como soluções para os problemas apresentados (BANCO MUNDIAL, 1967, p. 13, 48 -50).

Em 1971, o Banco Mundial (1971a; 1971b) organizou um projeto para educação no Brasil com base nas recomendações apontadas anteriormente e com aporte de recursos financeiros. Esse foi o primeiro empréstimo do Banco Mundial voltado à aplicação no setor educacional brasileiro, embora outros 30 empréstimos houvessem sido cedidos anteriormente. A proposta apresentada destina recursos para a criação de cursos de ensino técnico secundário e o pós-médio (BANCO MUNDIAL, 1971b, p. 2).

Esse Projeto estava vinculado a outro: Projeto Salto Osório cujo objetivo era a concessão de empréstimos para o setor energético, para aplicação na Eletrosul. Parte dos recursos desse segundo Projeto eram destinados ao treinamento na área de engenharia. Os recursos serviriam para construção de 16 instituições educativas, uma delas seria construída e administrada pelo Governo do estado de São Paulo e outras duas pela Universidade Federal de Santa Maria, no Rio Grande do Sul, conforme mencionado no Projeto (BANCO MUNDIAL, 1971b, p. 5). Vários outros acordos de empréstimo para implementação do projeto educacional com foco na EPT foram assinados a partir desse. Com base nesses acordos, foram realizadas auditorias a fim de verificar o desenvolvimento da aplicação do projeto (BANCO MUNDIAL, 1974; 1980; 1983a; 1983b).

Em 1978, foi sancionada a Lei $n^{\circ} 6.545 / 1978$ (BRASIL, 1978) que transformou as Escolas Técnicas Federais em CEFET. Logo no Art. $1^{\circ}$, essa Lei autoriza tais instituições a organizar e ministrar cursos de curta duração de Engenharia de Operação. A Lei não especifica se esses cursos seriam de nível médio técnico ou superior, mas confere autonomia administrativa, patrimonial, financeira, didática e disciplinar aos CEFET que seriam regidos 
por esse marco regulatório e por seus próprios estatutos e regimentos internos. Até que, em 1980, a Resolução CFE no 12/1980 (Cf.: BRASIL, 2002b) reformulou a denominação dos cursos de formação de tecnólogo, que passaram a ser denominados CST e os profissionais certificados nesses cursos chamados de tecnólogos.

Em 1988, o Decreto Federal no 97.333/1988 (BRASIL, 1988) autorizou a criação do primeiro CST em hotelaria ofertado pelo SENAC/SP. "A partir desse pioneiro curso do SENAC, outros se seguiram, do próprio SENAC, do SENAI e de outras instituições públicas e privadas de educação profissional em todo o País, diversificando, sobremaneira, a oferta de cursos superiores de tecnologia" (BRASIL, 2002a, p. 14).

Em 1989, a UNESCO organizou uma convenção destinada a tratar especificamente de educação técnica e profissional durante a $25^{\text {a }}$ Reunião da Conferência Geral, em Paris. A síntese dos direcionamentos para EPT parte da concepção de que "o ensino técnico e profissional responde ao objetivo global de desenvolvimento dos indivíduos e das sociedades" (UNESCO, 1989, p. 2). Evidencia-se, assim, a centralidade da política de educação profissional no bojo da própria política de educação, partindo do discurso do desenvolvimento humano na perspectiva da Teoria do Capital Humano e da Pedagogia das Competências. Conforme Art. $1^{\circ}$, educação técnica e profissional diz respeito a:

\footnotetext{
[...] todas as formas e níveis do processo de educação que inclui, além dos conhecimentos gerais, o estudo das técnicas e das disciplinas afins, a aquisição de habilidades práticas, de conhecimentos práticos e atitudes, e a compreensão dos diferentes ofícios nos diversos setores da vida econômica e social (UNESCO, 1989, p. 3).
}

A concepção de educação profissional presente no Documento é caracterizada pelo direcionamento ao pragmatismo e pela demanda por condução da subjetividade (atitudes) que, organicamente, orientam o desenvolvimento de competências (habilidades práticas) como objetivo desse processo educativo. Partindo desse fundamento conceitual, a educação técnica e profissional, segundo o acordo, deve adotar estruturas abertas e flexíveis sob a perspectiva da educação permanente, orientada pelas demandas do setor produtivo e desenvolvida em parceria com empresas não-educativas, para garantir o ingresso de todos os jovens no mundo do trabalho e a qualificação permanente dos adultos (UNESCO, 1989, p. 4-5).

Em 1990, a realização da "Conferência Mundial Sobre Educação Para Todos", em Jomtien, Tailândia, e do "Congresso Internacional sobre Planejamento e Gestão do Desenvolvimento da Educação", no México, demarcaram os rumos para política educacional global. Com base na afirmativa de que "Todo novo projeto de sociedade requer um novo projeto educativo"3 (UNESCO, 1991, p. 34), um projeto global para educação formal foi materializado em diversas reformas para área. O Documento evidencia o papel que o projeto educacional deve desempenhar e reforça que o "[...] ensino superior encontra, assim, um dos seus maiores desafios que se concentra, sobretudo, em poder

\footnotetext{
${ }^{3}$ Tradução livre do texto: “Todo nuevo proyecto de sociedad requiere de un nuevo proyecto educativo” (UNESCO, 1991, p. 34).
} 
desenvolver um novo pensamento e contribuir decididamente para um novo projeto cultural" (UNESCO, 1991, p. 65)4.

O papel das instituições de ensino superior no discurso hegemônico desse contexto é explorar formas de reunir o trabalho intelectual ao manual, de superar as teorias críticas e de construir bases teóricas para uma racionalidade libertadora, tanto em nível coletivo, quanto individual. Para isso, se torna necessário "mudar o conteúdo, as formas de ensinar, a estrutura do sistema, e criar classificações profissionais horizontais"5 (UNESCO, 1991, p. 44). É claro no Documento que todos esses pontos abordados estão, evidentemente, fundamentados na perspectiva economicista, na Teoria do Capital Humano cuja finalidade imediata é a produtividade/lucratividade a partir da educação formal. A direção do projeto educacional é conduzida para o aprofundamento do utilitarismo economicista cujo discurso aponta para ideia de indissociabilidade entre trabalho intelectual e manual, mas cuja essência fenomênica evidencia a intensificação da subsunção real do trabalho ao capital. Isso é claro na apresentação da proposta de uma pedagogia da autoaprendizagem com a utilização de tutores e sistemas informatizados e a formação de "engenheiros do conhecimento" sugeridas para transmissão de saberes e aumento da eficiência do treinamento (UNESCO, 1991, p. 72). Além do currículo centrado no conhecimento "socialmente útil", fundamentado na instrumentalidade, na técnica e nos procedimentos, na racionalização e simplificação dos conhecimentos (UNESCO, 1991, p. 80, 82).

Em 1992, a CEPAL (1992) apresentou um panorama da região da Latino-americana, seu projeto educacional e difundiu "ações exitosas" desenvolvidas por alguns países e que servem como exemplo para os demais. Assim, fomenta o nível pós-secundário como uma alternativa para diversificação de cursos, instituições, tipos de financiamento, sempre sob à égide da flexibilidade e racionalidade do mercado. Defende que "se pode estabelecer um sistema de formação pós-secundário para egressos do ensino médio técnico, com menções em áreas industriais específicas, ou em grupos articulados de setores" (CEPAL, 1992, p. $171)^{6}$. Para isso, levanta a bandeira de reforma curricular para equilibrar a relação custoqualidade na formação dos recursos humanos com vistas ao atendimento das demandas produtivas. Nesse mesmo ano, foi editado o Decreto no 2.208/1997 (BRASIL, 1997) que regulamentou a EPT e incluiu os níveis básico, médio técnico e tecnológico -

\footnotetext{
${ }^{4}$ Tradução livre do texto: “[...] educación superior encuentra, de esta forma, uno de sus mayores desafíos que se centra, ante todo, en ser capaz de elaborar un nuevo pensamiento y en contribuir decididamente a un nuevo proyecto cultural" (UNESCO, 1991, p. 65).

5 Tradução livre do texto: “[...] cambiar el contenido, las formas de enseñar, la estructura del sistema, y crear clasificaciones profesionales horizontales" (UNESCO, 1991, p. 44).

${ }^{6}$ Tradução livre do texto: “[...] se puede establecer un sistema de formación postsecundaria para egresados de la enseñanza técnica media, con menciones en áreas industriales específicas, o en grupos articulados de sectores” (CEPAL, 1992, p. 171).
} 
correspondente ao nível superior, destinado aos egressos do nível médio, conforme vinha sendo fomentado desde a década de 1960.

\section{O CST e a formação do trabalhador de novo tipo}

A regulação e desenvolvimento dos CST explicita o reordenamento da divisão social do trabalho educacional no bojo da política de educação hegemônica. Tal nível acadêmico desempenha alguns papeis na formação do trabalhador de novo tipo, em conjunto com outros instrumentos, para formação e conformação da classe trabalhadora à visão de mundo burguesa.

As bases para formação desse trabalhador de novo tipo, no contexto de recomposição burguesa, estão norteadas pelos preceitos do gerencialismo - expressão do máximo utilitarismo que fundamenta as relações de produção e reprodução da vida material no atual modelo de desenvolvimento do capital. Formação e conformação são as faces da educação para o trabalho combinadas organicamente para promoção e manutenção da concepção de mundo da classe dirigente. Essa concepção de educação tem como objetivo imediato a formação do cidadão-trabalhador que, em âmbito de desemprego estrutural, demanda do trabalhador a organização do seu próprio meio de subsistência. Desse modo, a formação do cidadão-empresa ocupa lugar de destaque para esse nível educacional. Para isso, os currículos dos CST são compostos por bases comuns voltados aos conteúdos de empreendedorismo, responsabilidade social, ética, sustentabilidade etc.

No contexto da recomposição burguesa, a reestruturação da produção provoca uma série de mudanças a partir da lógica do gerencialismo. A proposição de modos de produção pautados na flexibilidade e no accountability (responsabilidade) impulsiona o desenvolvimento de nova racionalidade aplicada à produção e reprodução no mundo do trabalho. A lógica do máximo utilitarismo expressa no chão da fábrica é tomada como modelo que orienta uma nova sociabilidade, na qual as ideias de lucratividade e produtividade, norteiam valores sociais hegemônicos para vida humana.

O perfil de trabalhador forjado pela lógica da flexibilidade e da responsabilidade, segundo a perspectiva hegemônica, é subsumido ao discurso dirigente de modo total. Flexibilidade e responsabilidade são destinadas ao condicionamento do trabalhador à servidão, à conversão ao espírito do capitalismo a ponto de o trabalhador entregar corpo e mente em prol da produção e da reprodução do modelo socioeconômico vigente. Para concretizar esse projeto, diversos instrumentos de conformação psicofísica são avocados como elementos na política de educação formal e não formal.

A educação para o trabalho em contraposição à ideia de educação profissional é tomada como um desses instrumentos da pedagogia política do capital para formação do trabalhador de novo tipo. A evidência disso como parte de um projeto global está expressa em diversos documentos dos organismos internacionais que analisamos neste artigo. 
Segundo a UNESCO (1996), a educação técnica e profissional deve ser reorientada para educação para o trabalho, sendo trabalho qualquer atividade humana, inclusive aquela à margem do mercado (UNESCO, 1996, p. 8). A orientação da UNESCO para a América Latina e o Caribe é que adotem o trabalho criativo, ampliem o setor informal, o autoemprego, as microempresas solidárias etc. Ao mesmo tempo, defende a importância de repensar acerca da pertinência da especialização técnica-profissional ao contexto e do papel do Estado como coordenador e fomentador da política de educação para o trabalho, do diálogo com a sociedade civil e da participação democrática.

A concepção de educação para o trabalho apresentada é uma maneira mais sutil de fomentar a política de conformação para o trabalho precário, para o subemprego, para o desemprego, propagando a lógica do cidadão-empresa. Para isso, o projeto hegemônico orienta a educação-trabalho de todos os sujeitos para o trabalho independente e empreendedor como estratégia de mediação do conflito de classes (Cf.: UNESCO, 1996, p. 83). Não se trata apenas de uma formação técnica originária do espaço escolar ou da formação profissional originária do setor produtivo. Educação-trabalho envolve sistemas de educação formal e não-formal que integram educação, trabalho, produção, ciência e tecnologia fundamentados numa dimensão ética e econômica de desenvolvimento (UNESCO, 1996, p. 14). Conforme apresentado no texto:

La reflexión acerca de los principios y prácticas que constituyen la tradición latinoamericana em materia de educación-trabajo es el camino para encontrar las promesas de cambio. Una lectura colectiva de los aciertos y las agendas pendientes y una revisión del núcleo de lo que se denomina la crisis de la educación técnica (ET) y la formación profesional (FP) son las estrategias para vislumbrar las futuras fortalezas allí donde podría percibirse sólo debilidade (UNESCO, 1996, p. 9).

A CEPAL (1998) divulgou um Documento endossando as orientações da UNESCO (1996). O texto apresenta as contradições presentes na demanda crescente de qualificação profissional do trabalhador e a demanda de desenvolvimento de uma reformulação dessa qualificação sob novos fundamentos mais adaptados ao contexto de avanço científico e tecnológico (CEPAL, 1998). Para fundamentar seu discurso sobre desregulação do trabalho e profissionalização renovada, argumenta sobre auto-organização, responsabilidade própria, racionalização centrada no sujeito pautados na ideia de competências e comportamentos voltados ao desenvolvimento do conhecimento a partir das experiências.

O principal argumento tomado pela CEPAL (1998) é o avanço do desemprego nos setores produtivos e a ampliação do setor de serviços que, combinados, fortalecem a demanda de uma qualificação profissional adequada para o contexto. Para isso, defende a ideia de mudanças no paradigma para formação do trabalhador a fim de uma profissionalização que desenvolva competências interdisciplinares e não apenas conhecimentos técnicos (CEPAL, 1998, p. 10).

Assim, a formação do trabalhador, em um contexto de erosão da ideia de profissão, segundo a perspectiva hegemônica, deve estar voltada a três objetivos: 1) desenvolver conhecimentos profissionais necessários, destreza e atitudes; 2) dispor de competências para solucionar problemas e cumprir tarefas profissionais de modo independente e flexível; 
e, 3) ser capaz e ter vontade de colaborar dentro da organização do trabalho (CEPAL, 1998, p. 11). Tais objetivos estão destinados ao objetivo principal de formar trabalhadores para atender aos sistemas, conforme o próprio Documento explicita.

Com base nesse mesmo argumento, a educação superior é encarregada de desenvolver o espírito empreendedor. O papel da educação superior, em um país como o Brasil, é:

\begin{abstract}
[...] formar os jovens com espírito empreendedor, ou em outras palavras, ajudá-los a conceber suas próprias empresas, é funda- mental. Para isso, além de introduções e de modificações pedagógicas no âmbito da formação, o desenvolvimento de incubadoras de empresas, dentro e fora das universidades, é elemento essencial. Mas, não se pode esquecer de que o mercado é mutável, e que o indivíduo tem, antes de tudo, de ser preparado para responder às necessidades sociais, e não às do mercado (UNESCO, 2012, p. 65).
\end{abstract}

Para isso, os modelos de Instituições de Ensino Superior (IES) mais apropriados à essa concepção de educação terciária são instituições não-universitárias e privadas, voltadas apenas para o ensino, que deve ocorrer, em grande parte, na modalidade à distância. Bem como, os modelos de cursos mais apropriados são aqueles mais focados nas demandas do mercado, com currículo enxuto e pautado no conteúdo pragmático, imediatista e interessado, com baixo custo operacional e flexibilidade no acesso. Esse modelo de curso foi desenvolvido a partir da regulamentação dos CST. Não por acaso, tais cursos foram insistentemente fomentados na política de educação global, no contexto de recomposição burguesa, como solução para as demandas atuais (Cf.: UNESCO, 1996, p. 24, 29, 42, 49, 84, $85,87,98,117,119$ e 120$)$.

\title{
Conclusão
}

A título de conclusão, a ampla reforma da educação, em nível global, foi impulsionada pela recomposição burguesa diante da crise orgânica do capital. Como resposta à essa crise de hegemonia, a retomada do consenso em torno da concepção de mundo burguesa requer a instrumentalização da política educacional para manutenção da sociabilidade nos padrões capitalistas.

A disputa entre capital e trabalho nesse contexto evidencia a sofisticação dos instrumentos utilizados no bojo da pedagogia política do capital, ao mesmo tempo em que impõe a intensificação da precariedade no mundo do trabalho. A garantia de manutenção da acumulação de capital está condicionada à conversão total do trabalhador ao espírito do capitalismo. Nesse ínterim, a formação do trabalhador de novo tipo engendra o desenvolvimento de mecanismos de conformação, como a educação terciária.

As estratégias de diversificação das IES nas sociedades periféricas do capitalismo vêm promovendo o desmantelamento da ciência brasileira e o aprofundamento das relações de dependência nas dimensões do conhecimento e tecnologia. Nesse sentido, a lógica de fragmentação que fundamenta a educação terciária impulsiona o crescimento de instituições não-universitárias e o desenvolvimento de uma formação fragmentada, 
aligeirada e voltada para um reordenamento do sistema de educação superior brasileiro. Nesse contexto, o ensino superior tecnológico se insere na lógica empresarial da educação interessada, pragmática e imediatista. $O$ crescimento desse nível da educação profissional expressa o desenvolvimento de instituições e cursos fragmentados, reformulando a dualidade educacional e restringindo as atividades de formação ao ensino.

A formação do trabalhador de novo tipo, nesse contexto, a partir dos CST, é destinada não apenas ao desenvolvimento de competências técnicas, mas à conformação à visão de mundo burguesa. Nesse sentido, o CST funciona como um instrumento na educação de nível superior destinado a formar e conformar. Formar de modo flexível para que o trabalhador desempenhe qualquer atividade laboral e conformar para que naturalize a intensificação da precariedade da vida no contexto de capitalismo avançado e reproduza os valores sociais da classe dirigente.

\section{Referências}

BANCO MUNDIAL. Economic growth of Brazil: problems and prospects. Vol VI: Education. Washington (DC): Western Hemisphere Department, 1967. 90 p.

BANCO MUNDIAL. Report and recommendation of the president to the executive directors on a proposed loan to Brazil for a technical and agricultural education project. Washington (DC): World Bank, 1971a. 23 p.

BANCO MUNDIAL. Loan agreement (education project) between Federative Republic of Brazil and International Bank for Reconstruction and Development. Washington (DC): World Bank, 1971b. 26 p.

BANCO MUNDIAL. Appraisal of a second education project Brazil. Washington (DC): World Bank, 1974. 67 p.

BANCO MUNDIAL. Project performance audit report Brazil first education Project. Washington (DC): Operations Evaluation Department, 1980. 92 p.

BANCO MUNDIAL. Report and recommendation of the president of the International Bank for Reconstruction and Development to the executive directors on a proposed loan in an amount the equivalent to US\$ $\mathbf{2 0 . 0}$ million to the Federative Republic of Brazil for a technician training project. Washington (DC), World Bank, 1983a. 38 p.

BANCO MUNDIAL. Loan Agreement (Technician Training Project) between Federative Republic of Brazil and International Bank for Reconstruction and Development. Washington (DC), World Bank, 1983b. 37 p.

BANCO MUNDIAL. Higher education in Brazil - challenges and options (English). Washington (DC), World Bank, 2002. 202 p.

BRASIL. Lei $\mathbf{n}^{\circ}$ 5.540, de 28 de novembro de 1968. Fixa normas de organização e funcionamento do ensino superior e sua articulação com a escola média, e dá outras providências. Brasília, DF, 1968. Disponível em: < https://www2.camara.leg.br/legin/fed/lei/1960-1969/lei-5540-28-novembro-1968359201-publicacaooriginal-1-pl.html>. Acesso em: 07/07/2019. 
BRASIL. Decreto-Lei $n^{\circ}$ 547, de 18 de abril de 1969. Autoriza a organização e o funcionamento de cursos profissionais superiores de curta duração. Brasília, DF, 1969. Disponível em: <http://www2.camara.leg.br/legin/fed/declei/1960-1969/decreto-lei-54718-abril-1969-374120-publicacaooriginal-1-pe.html>. Acesso em: 18/03/2018.

BRASIL. Lei $\mathbf{n}^{\circ}$ 5.692, de 11 de agosto de 1971. Fixa Diretrizes e Bases para o ensino de $1^{\circ}$ e $2^{\circ}$ graus, e dá outras providências. Brasília, DF, 1971. Disponível em: <https://www2.camara.leg.br/legin/fed/lei/1970-1979/lei-5692-11-agosto-1971-357752publicacaooriginal-1-pl.html>. Acesso em: 31/05/2019.

BRASIL. Lei $\mathbf{n}^{\circ}$ 6.545, de 30 de junho de 1978. Dispõe sobre a transformação das Escolas Técnicas Federais de Minas Gerais, do Paraná e Celso Suckow da Fonseca em Centros Federais de Educação Tecnológica e dá outras providências. Brasília, DF, 1978. Disponível em: <http://www.planalto.gov.br/ccivil_03/LEIS/L6545.htm>. Acesso em: 31/05/2019.

BRASIL. Decreto n' 97.333, de 21 de dezembro de 1988. Autoriza o funcionamento do curso superior de Tecnologia em Hotelaria do Instituto Superior de Hotelaria e Turismo, em São Paulo, Estado de São Paulo. Brasília, DF, 1988. Disponível em: < https://www2.camara.leg.br/legin/fed/decret/1988/decreto-97333-21-dezembro-1988-

447601-publicacaooriginal-1-pe.html>. Acesso em 14/09/2019.

BRASIL. Decreto $\mathbf{n}^{\circ} \mathbf{2 . 2 0 8}$, de 17 de abril de 1997. Regulamenta o $\S 2^{\circ}$ do art. 36 e os arts. 39 a 42 da Lei $n^{\circ}$ 9.394, de 20 de dezembro de 1996, que estabelece as diretrizes e bases da educação nacional. Brasília, DF, 1997a. Disponível em: <http://www.planalto.gov.br/ccivil_03/decreto/d2208.htm>. Acesso em: 08/04/2017.

BRASIL. Parecer CNE/CP $\mathbf{n}^{\circ} 29$ de 03 de dezembro de 2002. Diretrizes Curriculares Nacionais Gerais para a Educação Profissional de Nível Tecnológico. Brasília, DF, 2002a. Disponível em: <http://portal.mec.gov.br/cne/arquivos/pdf/cp29.pdf>. Acesso em: 13/09/2019.

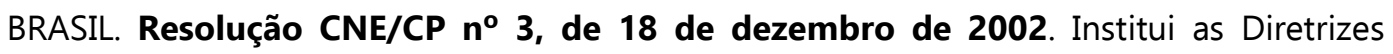
Curriculares Nacionais Gerais para a organização e o funcionamento dos cursos superiores de tecnologia. Brasília, DF, 2002b. Disponível em: < http://portal.mec.gov.br/cne/arquivos/pdf/CP032002.pdf>. Acesso em: 02/06/2018.

BRASIL. Decreto $\mathbf{n}^{\circ} \mathbf{5 . 1 5 4}$, de 23 de julho de 2004. Regulamenta o $§ 20$ do art. 36 e os arts. 39 a 41 da Lei no 9.394, de 20 de dezembro de 1996, que estabelece as diretrizes e bases da educação nacional, e dá outras providências. Brasília, DF, 2004a. Disponível em: <https://www.planalto.gov.br/ccivil_03/_Ato2004-2006/2004/Decreto/D5154.htm >. Acesso em: 02/04/2017.

CEPAL. Boletín Económico de América Latina. CEPAL: Santiago de Chile, Vol. VII, No. 2, octubre de 1962.

CEPAL. Educacion y conocimiento: eje de la transformacion productiva con equidad. CEPAL: Santiago de Chile, 1992. 247 p.

CEPAL. Cambios tecnológicos y organizativos em la formación profesional. CEPAL: Santiago de Chile, 1998. 59 p.

CUNHA, Luiz Antonio. A universidade reformanda: o golpe de 1964 e a modernização do ensino superior. Rio de Janeiro: Ed. Francisco Alves, 1988. 332 p. 
FERNANDES, Florestan. Capitalismo dependente e classes sociais na América Latina. $4^{\mathrm{a}}$ edição. São Paulo: Global, 2009.

MACEDO, Jussara Marques de. Formação para o trabalho docente. Curitiba: Appris, 2017.

SANTOS, Deribaldo Gomes; JIMÉNEZ, Susana Vasconcelos. Graduação Tecnológica no Brasil: aproximações críticas preliminares. Revista Linhas Críticas. V. 15, n. 28, p. 171-185, 2009.

SOUZA, José dos Santos. Crise orgânica do capital, recomposição burguesa e intensificação da precariedade do trabalho docente: fundamentos sócio-históricos da (des)configuração do trabalho docente. In: SILVA Jr., João dos Reis et al. Das crises do capital às crises da educação superior no Brasil: novos e renovados desafios em perspectiva. Uberlância (MG): Navegando, 2019. p. 19-36.

SOUZA, José dos Santos. Mediação entre a Escola e o Novo Mundo do Trabalho na Formação de Técnicos de Nível Médio. Trabalho, Educação e Saúde (online), v. 16, p. 123140, 2018.

SOUZA, José dos Santos. Reforma Gerencial e Novos Desafios para a Gestão do Trabalho Escolar. RTPS - Revista Trabalho, Política e Sociedade, v. 1, p. 09-20, 2016.

UNESCO. La enseñanza professional y técnica: bibliografia internacionaI. Paris: UNESCO, 1959. $70 \mathrm{p}$.

UNESCO. The work of UNESCO in the field of Higher Scientific and Technological Education. Paris: UNESCO, 1962. 8 p.

UNESCO. Conferencia Internacional sobre Planeamiento de la Educación: informe final. Paris: UNESCO, 1968. 78 p.

UNESCO. Actas de la Conferencia General: resoluciones. Vol. 1. Paris, 1970. 157 p.

UNESCO. Convención sobre la Enseñanza Técnica y Profesional. 25a Reunião da Conferéncia General. París: UNESCO, 1989. 9 p.

UNESCO. Documento Base. Reunião internacional de reflexión sobre los nuevos roles de la educación superior a nivel mundial, el caso de America Latina y el Caribe. CRESALC: Caracas, Venezuela, 1991. 127 p.

UNESCO. La educacion tecnica y la formacion profesional. Santiago: UNESCO, 1996. 132 p.

UNESCO. Desafios e perspectivas da educação superior brasileira para próxima década: 2011-2020. UNESCO, CNE, MEC: Brasília, DF, 2012. 164 P.

\section{Informações sobre os autores:}

\section{Célia Cristina Pereira da Silva Veiga}

Doutora em Educação pela Universidade Federal Rural do Rio de Janeiro (UFRRJ). Atua como Coordenadora de Ensino da Escola de Inteligência de Segurança Pública do Estado do Rio de Janeiro (ESISPERJ), vinculada à Subsecretaria de Inteligência da Secretaria de 
Estado de Polícia Civil do Rio de Janeiro. É pesquisadora do Grupo de Pesquisas Sobre Trabalho, Política e Sociedade (GTPS/UFRRJ), é membro associada da Associação Nacional de Pós-graduação e Pesquisa em Educação (ANPED) e da Associação Nacional de Política e Administração da Educação (ANPAE).

ORCID iD: https://orcid.org/0000-0003-4932-5968

E-mail: celiacveiga@gmail.com

\section{Bruno de Oliveira Figueiredo}

Doutor em Educação pela Universidade Federal Rural do Rio de Janeiro (UFRRJ). Atua como Professor da Fundação de Apoio à Escola Técnica do Estado do Rio de Janeiro (FAETEC) e como professor convidado do Curso de Especialização Lato Sensu em Gestão Educacional (CEGEd) da UFRRJ. É membro do Grupo de Pesquisas sobre Trabalho, Política e Sociedade (GTPS), é membro do Comitê Editorial da Revista Trabalho, Política e Sociedade (RTPS), é membro associado da Associação Nacional de Pós-Graduação e Pesquisa em Educação (ANPEd) e da Associação Nacional de Política e Administração da Educação (ANPAE) e integra a Rede de Pesquisadores Universitas-BR. Premiado com a Moção por Dedicação e Contribuição ao Aprimoramento Contínuo do Ensino Superior Carioca pela Câmara Municipal do Rio de Janeiro (2016).

ORCID iD: https://orcid.org/0000-0002-1099-2010

E-mail: mbrunosaar@gmail.com

Submetido em: $16 / 03 / 2020$

Aprovado em: $10 / 04 / 2020$

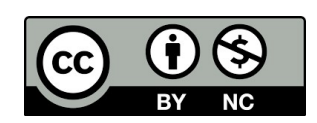

Esta obra está licenciada com uma Licença Creative Commons Atribuição - Não Comercial 4.0 Internacional 